\title{
Adaptation of a Young College Teacher to Professional Activity
}

\author{
Elena Krolevetskaya ${ }^{1},{ }^{*}$ Daria Nedostupenko ${ }^{1}$, Natalia Shekhovskaya ${ }^{1}$, Olga \\ Muromtseva $^{1}$
}

\author{
${ }^{1}$ Belgorod National Research University, Russia \\ *Email: krolevetskaya@bsu.edu.ru
}

\begin{abstract}
The relevance of the study is due to the contradictions characteristic of the field of secondary vocational education, namely, the discrepancy between the requirements for the professional activity of a college teacher and their implementation in their professional activity in specific working conditions; the ageing of teaching staff and the lack of a system of adaptation of young teachers in educational organisations. The purpose of the study was to identify problematic aspects in the activities of young college teachers, as well as to identify factors that contribute to the creation of favourable conditions for their professional adaptation. The article presents the results of an empirical study of the problems and factors of professional adaptation of young college teachers aged 22 to 30 years. The most significant difficulties for novice teachers are caused by the issues of the relationship between the teacher and students, the young specialist with colleagues, methodological aspects of the lesson, documentation, curatorship. The survey revealed the need for young teachers in psychological, pedagogical, methodological, socio-economic support of their professional adaptation, in individual mentoring.
\end{abstract}

Keywords: Young college teacher, Professional adaptation, Factors of professional adaptation.

\section{INTRODUCTION}

The period of adaptation plays an essential role in the professional development and formation of a young college teacher. Even with a sufficiently high level of readiness for pedagogical activity, the personal and professional adaptation of a young teacher who has started working can take a long time.

The problem of adaptation is an important area of research located at the intersection of various fields of knowledge. Issues of professional adaptation are studied in sociology, psychology, pedagogy, management, and economics.

In management, adaptation is considered one of the most critical areas of personnel management practice in a modern organisation. It is, on the one hand, a mechanism for employee interaction with the organisational environment, and on the other hand, one of the methods for developing the potential of the organisation's human resources [1-3]. From the sociology point of view, professional adaptation can be considered as the interaction of the individual and the professional environment, the "entry" of the individual into new social and professional roles. The combination of external and internal factors ensures optimal functioning and development of the individual in the profession and contributes to the assimilation of values and norms of the professional activity of young specialists [4,5]. In psychology, the category of professional adaptation is defined as the adaptation of an individual to a new type of professional activity, new working conditions, and social environment. The psychological aspect of professional adaptation is manifested in the development of a stable positive attitude to the chosen profession, in the appearance of a subjective sense of satisfaction with this type of activity [6]. It is associated with overcoming a high level of anxiety, increased fatigue, emotional exhaustion and burnout [7-10]. I.A. Karpovich, I.S. Voronova research showed that the main psychological 
problems faced by a novice teacher are: the need for a new role distribution and the establishment of interpersonal contacts; the inability to establish an optimal distance with students and maintain discipline; a high level of anxiety and self-doubt [7, p.109].

European and American researchers [11,12] also note the difficulties that a novice teacher most often faces in the process of adaptation: lack of professional experience, high loads, lack of respect from society, continuous changes, student behaviour, external supervision of the educational process, low salaries, cultural and professional isolation, lack of opportunities for career growth. Without professional support of an experienced mentor (tutoring, coaching, mentoring), these problems often lead to the dismissal of a young employee [13-16]. According to R. Ingersoll, necessary adaptation measures for a novice teacher, are regular supportive communication with the director, other employees of the administration; constant guidance and feedback from the mentor-teacher; cooperation and joint time planning with other teachers in the same subject area; the presence of an assistant teacher in the classroom; reducing the learning load [16, p.50].

Despite a significant amount of scientific research in this direction, many issues related to the professional and pedagogical formation of a college teacher, his adaptation to a new place, remain open, and the possibilities of improving the effectiveness of this process are not fully used.

Professional adaptation of a young college teacher, in our opinion, is a process of interaction between the individual and the professional environment, during which the optimal compliance of the teacher professional abilities with the educational organisation requirements are achieved. Professional adaptation is a two-way process between a person and a new social and professional environment.

The relevance of the presented research is due to the existing contradictions characteristic of the professional activities of young college teachers. On the one hand, the contradictions are related to the discrepancy between the set of requirements for the professional activity of a college teacher and their implementation in professional activity in specific working conditions. On the other hand, in the field of secondary vocational education, there is an ageing of the teaching staff; there is an increasing demand for young teachers. In connection with this circumstance, there is a need to create appropriate conditions for securing young personnel in an educational organisation, providing opportunities for continuous growth, professional development and advanced training, creating programs for adaptation and professional support (mentoring) of young teachers $[16,17]$.
Creating an effective system of adaptation of a young teacher is a multidimensional task: this includes financial support, a system of moral rewards and incentives, psychological adaptation in the team, and methodological training. Some of them (for example, financial support or the problem of the profession in society prestige) are not within the competence of the administration of the educational organisation. But the problems of psychological adaptation in the team, creating an emotionally favourable atmosphere, methodological assistance to a young specialist can be solved within the walls of an educational institution. Thus, the relevance and social significance of this issue are not in doubt.

The purpose of the study is to identify problem areas in the activities of young college teachers, as well as to identify factors that contribute to the creation of favourable conditions for their professional adaptation.

\section{RESEARCH METHODOLOGY}

The study was conducted based on the theoretical analysis of scientific literature, analysis of practical experience, use of questionnaires in the empirical part of the study, methods of mathematical data processing.

The study involved 56 young teachers aged 22 to 30 years, working in organisations of secondary vocational education in the city of Belgorod and the Belgorod region, with work experience from several months to 4 years. Of these, $30 \%$ are teachers with less than one year of work experience, $26 \%$ are teachers with up to 2 years of work experience; $22 \%$ are teachers with up to 3 years of work experience, and $22 \%$ are teachers with up to 4 years of work experience. The main part $(82 \%)$ of the surveyed young teachers were women, $18 \%$ - men.

In our opinion, the questionnaire is the most appropriate tool for this study, which will provide an understanding of the problem, maximise the rational use of respondents ' time and facilitate data analysis. The survey was aimed at identifying: 1) problems faced by a novice teacher in the professional, psychological and motivational component of adaptation; 2) resources that can be used to eliminate the identified problems.

\section{THE STUDY RESULTS}

The analysis of the results showed that the most challenging issues for young teachers are the relationship between the teacher and students, the young specialist with colleagues, methodological aspects of the lesson, documentation, and supervision. When asked whether you are satisfied with your professional training level, $66.7 \%$ of respondents answered in the affirmative and $33.3 \%$ - in the negative. A young specialist at the beginning of his career has a sufficient level of theoretical knowledge. Still, at the same time, an insufficient level 
of practical skills and formed professionally essential qualities. Therefore, it is vital to provide constant methodological assistance to young teachers, to organise mentoring by more experienced teachers $[14,18]$. In the course of our research, it was determined that $100 \%$ of young teachers seek help from their colleagues.

It was determined that the main reason that most causes dissatisfaction with the work of young college teachers is excessive workload at work $(61.5 \%$ of respondents noted). A young teacher is unprepared for a considerable number of assignments, documentation, which "fall" on him from the first days of work in college. Also, many teachers noted such reasons for dissatisfaction with work as the attitude of parents to teachers $(35.9 \%)$, low wages $(33.3 \%)$, lack of time for self-education $(30.8 \%)$, lack of students ' desire to learn (30.8\%) (figure 1).

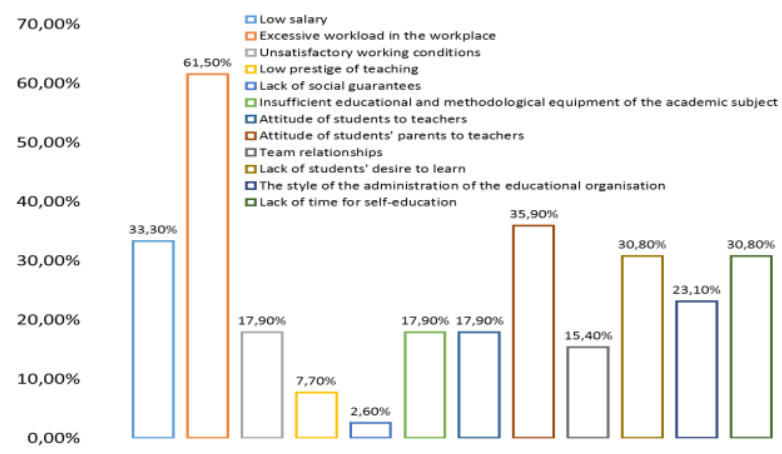

Figure 1 Reasons for dissatisfaction with the work of young college teachers.

Of course, any specialist who is just starting his professional way is experiencing difficulties due to lack of experience. But, in our opinion, the formation of a young teacher is more complicated, more acute than a representative of any other profession, because the education system does not provide them with a decent "launchpad" in the form of financial, methodological, and psychological support.

Among the socio-economic problems that young college teachers most often face, the financial issue is in the first place. Dissatisfaction with wages was noted by most of the respondents- $84 \%$. The remuneration of teaching staff of the college has its specifics, which mainly consists in the direct dependence of the employee's salary on his qualification category (first or highest) and to a certain extent on the length of service. The salaries of young college teachers are not high. At the same time, the number of hours per bid is usually inversely proportional to the position held: the lower the position, the more hours. Therefore, in addition to working in college, young teachers have to solve their material problems by combining with other types of earnings, which, of course, can not but affect the quality of preparation for classes. That is why working in college for many turns into a job "for the soul" (who can afford it). The predominant number of respondents in terms of material well-being consider themselves to be middleincome- $62 \%$ and low-income-38\%.

The analysis of the data allowed us to identify areas of the organisation of the educational process in the college, in which a young teacher needs methodological assistance (figure 2). A large group of respondents found difficulties in communicating with students and their parents $(27 \%)$, in the calendar and thematic planning $(21.6 \%)$, in communicating with the administration $(13.5 \%)$, in conducting extracurricular activities and in conducting lessons $(13.5 \%)$.

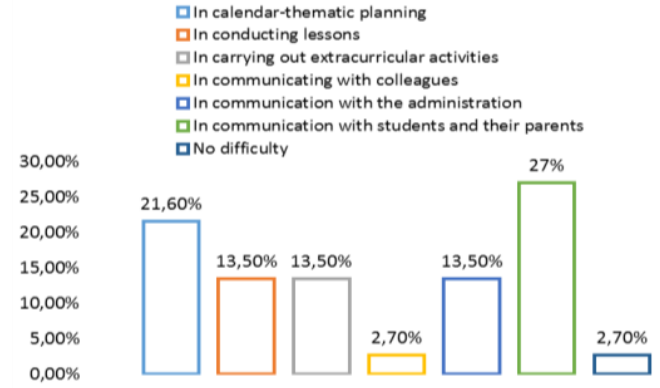

Figure 2 Difficulties of young college teachers in organising the educational process.

The study revealed that young teachers are in urgent need of developing their professional competence. Among the various forms of professional competence improvement, respondents gave the most significant preference to individual assistance from a mentor (56.4\%), master classes $(53.8 \%)$ and self - education $(51.5 \%)$ (figure 3$)$. This suggests that young teachers trust their colleagues more and try to learn from their mentors.

We also analysed the topics of masterclasses and practice-oriented seminars, which are relevant for young college teachers (figure 4). Respondents noted the following topics of seminars as the most relevant and useful: "Conflict resolution" (61.5\%), "Teaching methods and their effective use in the educational process" (48.7\%), "Accounting and evaluation of students 'knowledge" (46.2\%), "Forms of work with parents" $(41 \%)$. The choice of topics indicates the need for young teachers in psychological and methodological knowledge, practical advice in the field of pedagogical interaction with students and their parents.

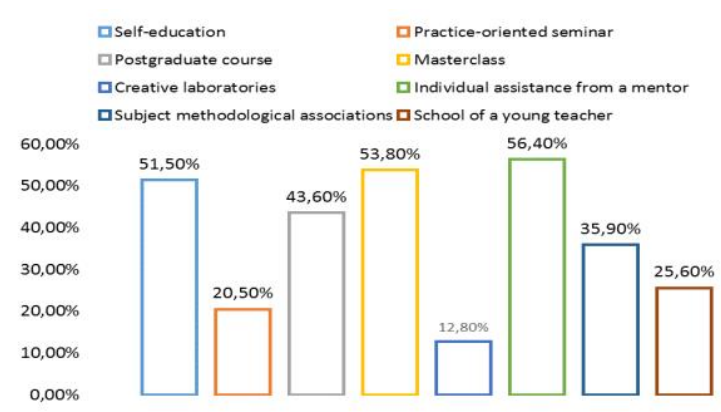


Figure 3 Preferred forms of professional competence improvement by young teachers.

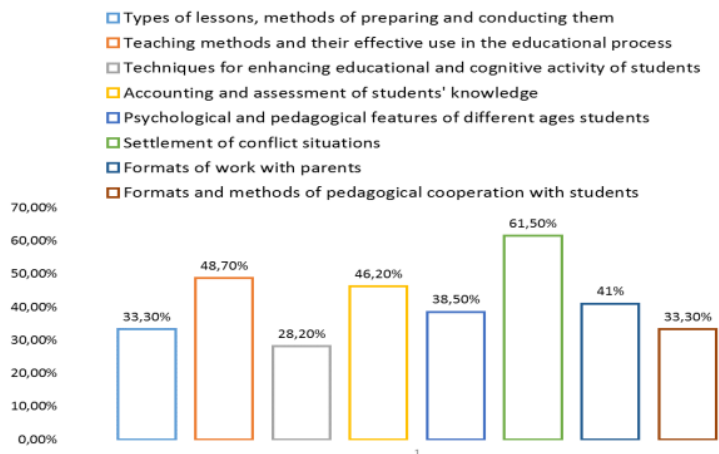

Figure 4 Topics of masterclasses and practice-oriented seminars.

Respondents were also asked to answer the question of whether your attitude to the chosen profession has changed after starting your professional activity (figure $5)$.

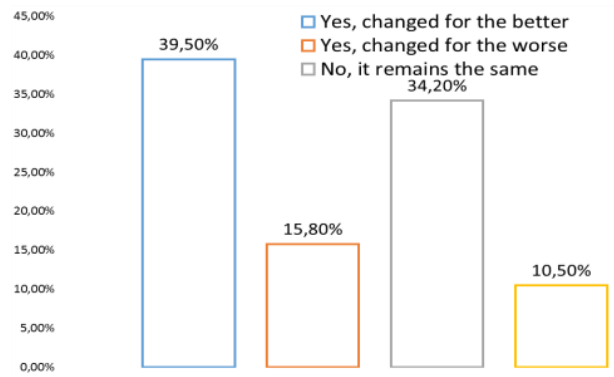

Figure 5 Change of attitude to the chosen profession after the beginning of the professional activity.

The analysis of the answers showed that $39.5 \%$ of respondents' attitude to the chosen profession changed for the better after starting their professional activity, $34.2 \%$ of respondents noted that their attitude to work remained the same, $10.5 \%$ of respondents found it difficult to answer. The alarm is caused by $15.8 \%$ of young teachers who noted that the work attitude has changed for the worse. This states that young teachers who have just started working very often are left alone with their difficulties. In educational organisations that do not have a program for the adaptation of young teachers, there is a tendency for novice teachers to leave in the first year of work [11].

\section{CONCLUSIONS}

The study made it possible to identify the main factors that positively or negatively affect the adaptation of young college teachers. Among the positive factors, we attributed positive relationships with colleagues, students, a convenient schedule and the ability to combine work in college with other activities. Negative factors are low salary, insufficient level of material well- being, a large number of "paper" work; low motivation of students to study; lack of pedagogical experience; lack of time; an enormous psychological and emotional burden; relations with the college administration; defective material and methodological support of the educational process. An essential condition necessary for the successful professional adaptation of a novice teacher is the creation and implementation of adaptation programs in secondary vocational education organisations aimed at psychological, pedagogical, methodological, socioeconomic support of young teachers. Thanks to the individual support of the mentor, the young teacher get the opportunity to overcome their deficits and difficulties, and the college acquires a qualified teacher who connects his professional future with this organisation.

\section{REFERENCES}

[1] E.P. Bondareva, S.A. Sergeev, Factors of professional adaptation of young university teachers, Knowledge. Understanding. Skill, Iss. 2, 2016,

DOI: http://dx.doi.org/10.17805/zpu.2016.2.23

[2] N.V. Samoukina, Personnel adaptation: problems and opportunities, personnel development management 1(61) (2020) 22-30. DOI: https://doi.org/10.36627/2619-144X-2020-1-1-22$\underline{30}$

[3] S.A. Sopoev, Adaptation of young specialists as one of the problems of staffing Russian organisations, Bulletin of the North Ossetian State University named after K.L. Khetagurov. Social Sciences 2 (2012) 251-253. Retrieved from: https://www.elibrary.ru/item.asp?id=18444224\&

[4] E.G. Chernikova, Features of social and professional adaptation of young teachers of secondary schools, Bulletin of the Chelyabinsk State University. Education and Healthcare 4 (2014) 150153. Retrieved from: https://www.elibrary.ru/item.asp?id=21682877

[5] N.A. Shaidenko, S.M. Redlich, V.G. Podzolkov, Features of preparation for the pedagogical activity, ensuring successful social and professional adaptation of the future teacher, Psychology of personal and professional development: modern challenges and risks: materials of the XII International scientific and practical conference, Pero Publishing House, Moscow, 2016, pp. 74-78. Retrieved

from: https://www.elibrary.ru/item.asp?id=27361720

[6] N.A. Yershova, An adaptation of students of pedagogical specialities to professional activity, 
Publishing House of the Orsk Humanitarian and Technological Institute, 2003, 307 p.

[7] I.A. Karpovich, 1.S. Voronova, The adaptation of young university teachers with work experience of 1-3 years and 3-5 years, Azimut of scientific research: pedagogy and psychology Vol. 9 Iss. 2(31) (2020) 106-110. Retrieved from: http://repository.kvantor.org/public/44/1725

[8] S.D. Reznik, Barriers to the formation of young teachers, Higher Education in Russia 12 (2012) 112$117 . \quad$ Retrieved from: https://cyberleninka.ru/article/n/bariery-na-putistanovleniya-molodogo-prepodavatelya/viewer

[9] H. Yinon, L. Orland-Barak, Career stories of Israeli teachers who left teaching: a salutogenic view of teacher attrition, Teachers and Teaching Vol. 23 Iss. 8 (2017) 914-927.

[10] M. Çakmak, M. Gündüz and A.B. Emstad, Challenging moments of novice teachers: survival strategies developed through experiences, Cambridge Journal of Education, 2019. DOI: https://doi.org/10.1080/0305764X.2018.1476465

[11] K. Struyven, G. Vanthournout, Teachers' exit decisions: An investigation into the reasons why newly qualified teachers fail to enter the teaching profession or why those who do enter do not continue teaching, Teaching and teacher education Vol. 43 (2014) 37-45.

[12] E.A. Bettini, N.D. Jones, M.T. Brownell, M.A., Conroy and Leite W. L., Relationships Between Novice Teachers' Social Resources and Workload Manageability, Journal of Special Education, 2018. DOI: https://doi. org/10.1177/0022466918775432

[13] A.P. Chernyavskaya, L.N. Danilova, The role of a teacher-mentor in the adaptation of a young teacher, Yaroslavl Pedagogical Bulletin 4(109) (2019) 62$70 . \quad$ Retrieved from: https://www.elibrary.ru/item.asp?id=39289497

[14] J. Cammerer, V. Ziegler, S. Bartonek, Tutoring and coaching as unique forms of mentoring when entering the profession of young teachers (trans. from German by L.N. Danilova), Yaroslavl Pedagogical Bulletin 1(106) (2019) 56-69. Retrieved from: https://www.elibrary.ru/item.asp?id=37005170

[15] M. Keller-Schneider, U.H. Beginning, Teachers' Appraisal of Professional Requirements and Implications for Teacher Induction in Switzerland, Education and Self Development, Vol. 14 Iss. 3 (2019) 62-79. DOI: https://doi.org/10.26907/esd14.3.07
[16] R. Ingersoll, Beginning Teacher Induction: What the Data Tell Us, Phi Delta Kappan 93(8) (2012) 47 51. Retrieved from: http://www.kappanmagazine.org/content/93/8/47

[17] A.R. Alaverdov, T.P. Alaverdova, Organization of the process of professional and psychological adaptation of young teachers of higher education, Higher education in Russia 4(200) (2016) 5-16. Retrieved from: https://www.elibrary.ru/item.asp?id=25867178

[18] L. Paula, A. Grīnfelde, The Role of Mentoring in Professional Socialization of Novice Teachers, Problems of Education in the 21st Century, 2018, Retrieved from: http://www.mendeley.com/research/rolementoring-professional-socialization-noviceteachers 